\title{
Visual backward masking and the area-detection relation ${ }^{1}$
}

\begin{abstract}
MICHAEL F. SHERRICK and WILLIAM N. DEMBER, University of Cincinnati, Cincinnati, Ohio 45221
\end{abstract}

Contrary to expectations based on the well-documented positive relation between target area and detectability, half-black and half-white target disks were considerably more difficult to mask (easier to detect) with black rings than was a homogeneous black disk. The results, obtained by a forced-choice indicator response, can probably be attributed to the contour effects generated by the black-white disks. These findings indicate that the area-detection relation (and possibly other well-known psychophysical relations) may not generalize to masking situations.

The retroactive interference with the perception of a target stimulus by a subsequently presented masking stimulus ("backward masking") has been extensively investigated (see Kahneman, 1968; Raab, 1963), but few experiments have directly examined the relationship between masking and the data and laws of classical psychophysics. In the present study, we assess the validity of the well-known area-detection relation of classical psychophysics as generalized to the backward masking situation.

Numerous studies (Blackwell, 1946; Bouman \& Blokhuis, 1952; see review by Brown \& Mueller, 1965, pp. 211-213) show target detectability to be an increasing function of the area of the target stimulus. Although the validity of the various laws (e.g., Ricco's law, Piper's law) proposed to describe the exact form of this function is somewhat controversial, the positive relation between area and detection is unquestioned. Since the S's task is often identical in simple detection and masking experiments, it seems reasonable to expect the area-detection relation to hold for the masking situation: Larger targets should be harder to mask (easier to detect) than smaller targets. Our data, reported below, show just the opposite.

In order to test the validity of the area-detection relation in masking situations, we compared the backward masking of half-black and half-white disks with that of a homogeneous black disk. We chose those configurations to fit a conclusion of Werner's (1935) that heterogeneous targets are harder to mask than are homogeneous targets. Thus, there is a basis in Werner's work for expecting greater detection of the black-white than of the homogeneous black target. According to the area-detection relation, however, the black-white disks should be relatively difficult to detect (easy to mask), since such targets on a white background are, in effect, black semi-disks, half as large as the homogeneous black disk.

\section{SUBJECTS}

Five male and five female college students served as Ss. All had normal or corrected-to-normal vision. Before the start of the experiment proper, each $S$ received approximately 1,500 training trials. Some of the forthcoming experimental target stimuli were presented during the training sessions.

\section{STIMULI}

The stimuli were black ink drawings on white index cards. The mask was always a pair of identical black rings (see Fig. 1). Two rings were used in order to accommodate the spatial forced-choice indicator response that was employed. The E placed the target-disk so that it fit snugly within one of the two rings; disk location on a given trial was random. The Ss indicated the locus of the disk by responding "left" or "right" on each trial, guessing when necessary. The advantages, reliability, and validity of this two-altemative, spatial, forced-choice indicator response have been documented (Heckenmuller \& Dember, 1965).

Two major types of targets were constructed: (1) the conventional, homogeneous black disk and (2) disks that were half-black and half-white. The various black-white disks are depicted in Fig. 2. Eight varieties of black-white disks were used in order to control for potential effects of stimulus orientation (vertical-horizontal), position (left-right; top-bottom) of the stimuli, and presence or absence of a black border.
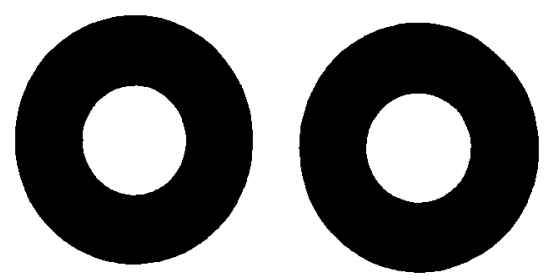

Fig. 1. The mask. Two rings were used in order to accommodate the forced-choice indicator response.
The diameter of the full target-disks and inside diameter of the rings subtended 26 min of visual arc. ${ }^{2}$ The outside diameter and width of the black wall of the rings were 54 and $14 \mathrm{~min}$ of arc, respectively. The distance between ring centers subtended $66 \mathrm{~min}$ of visual arc.

\section{PROCEDURE}

A given experimental condition was presented to $S$ in blocks of 25 successive trials. Sixteen such conditions were identified in order to assure an equal number of trials for each of the two major types of target-disks (homogeneous black and black-white). Eight of the conditions were defined by the eight black-white disks. The other eight conditions consisted merely of eight different presentations (in blocks of 25 trials) of the homogeneous black disk. The blocks of 16 experimental conditions were presented in a different random order in each of two daily testing sessions. Moreover, the order of presentation of the conditions was randomized independently for each $S$. Before the presentation of an experimental condition, the $S$ s helped $E$ center the target-disk in each of the pair of rings; the Ss, therefore, always knew which target was actually being used in a given block of trials.

The completion of the experiment yielded a total of 400 trials on the homogeneous black disk and 50 trials on each of the eight black-white disks for 9 of the $10 \mathrm{Ss}$. One S became ill and completed only one daily session; she viewed the homogeneous black disk for 200 trials and each of the eight black-white disks for 25 trials.

The stimuli were presented tachistoscopicaliy (Scientific Prototype, Model GX). Each trial consisted of the following sequence: fixation field, target field, mask field, fixation field. The Ss initiated each trial after a "ready" signal from $E$; an average interval of $5 \mathrm{sec}$ separated successive trials. The durations of the target and masking flashes were 15 and $105 \mathrm{msec}$, respectively. The termination of the target flash defined the onset of the masking flash (the interstimulus interval was $0 \mathrm{msec}$ ). The fixation field remained on between trials. The luminance of each field was $25 \mathrm{ft}-\mathrm{L}(26.9 \mathrm{~mL})$. Viewing was monocular.

\section{RESULTS}

The raw scores (number of correct detections) were converted to proportions and corrected for guessing. Averaged over all $10 \mathrm{Ss}$, the mean per cent correct detection of all black-white disks was 45.6\%; mean per cent correct detection of the homogeneous black disk was $17.5 \%$. A $t$ test for correlated samples indicated this difference was statistically significant 


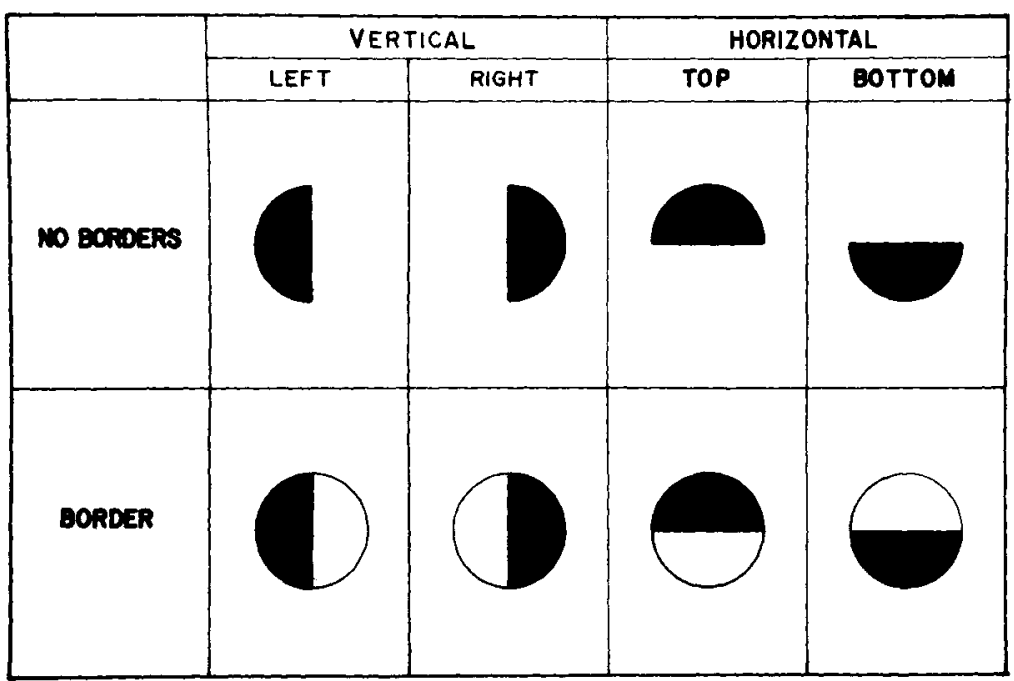

$(t=3.58, \quad d f=9, \quad p<.01, \quad$ two-tailed $)$. Differences among the detection scores of the eight black-white disks were negligible. DISCUSSION

In brief, masking was considerably greater (detection less) for the homogeneous black disk than it was for the half-black and half-white disks. These results clearly support the expectation based on Werner's data and disconfirm the prediction generated from the area-detection relation. At least in the present study, the well-documented relation between target area and detectability does not apply to backward masking.

The failure of the area-detection relation to hold in the present experiment can probably be attributed to the contour effects generated by the black-white disks. These targets contain internal contours, whereas the homogeneous black disk does not. The relatively good detection of the black-white disks, therefore, follows logically from the results of those studies (Pollack, 1965; Werner, 1935) that show targets with internal contours to be relatively difficult to mask. In addition, the relatively good detection of the black-white disks is probably due in part to the spatial separation of the ring contour and the linear border of the black-white disks. Several experiments (Cox, Dember, \& Sherrick, 1969; Streicher \& Pollack, 1967; Sturr \& Frumkes, 1968) show that masking decreases markedly as the distance between target and mask contour increases. The present results suggest the possibility that other well-established psychophysical relations may not be applicable to the masking situation. In fact, Purcell, Stewart, \& Dember (1969) note a facilitation of backward masking (a decrease in detection) when either the luminance or the duration of the target is increased. Such results, of course, are the exact opposite of the positive relation between target luminance/duration and target detectability typically observed in simple detection experiments. When considered together with those results, our study indicates that generalizations from nonmasking to masking situations should be made with caution.

\section{REFERENCES}

BLACKWELL, H. R. Contrast thresholds of the human eye. Journal of the Optical Society of America, 1946, 36, 624-643.

BOUMAN, M. A., \& BLOKHUIS, E. W. M. The visibility of black objects against an
Fig. 2. The eight half-black and half-white target disks. The columnar headings indicate the orientation and position of the targets with respect to the Ss.

illuminated background. Journal of the Optical Society of America, 1952, 42, 525-528.

BROWN, J. L., \& MUELLER, C. G. Brigh tnes: discrimination and brightness contrast. In C. H. Graham tid.). Sision and ristal peréption. New York: Wikey. 1965. Pp. $2(18-250$.

COX, S. I., DEMBER. W. N., \& SHERRICK, M. l. Effect on backward masking of yatial separation hetween target and mask comtours backward masking. Psichonomi silence. 1965. 3. 167-168.

HECKENMLELLER, E. G., \& DEMBER, W. N. A forced-choice indicator for use with Werner's disc-ring pattern in studies of backward masking. Psychonomic Science. $1965,3,167-16$.

KAHNEMAN, D. Method, findings, and theory in studies of visual masking. Psychological Bulletin, 1968, 70, 404-425.

POLLACK, R. H. Effects of figure-yround contrast and contour orientation on figural masking. Psychonomic Science, 1965, 2 , 369.370.

PURCELL. D. G., STEWART, A. L., \& DEMBER, W. N. Backward masking: Facilitation through increased target-field luminance and duration. Psychonomic Science. $1969,15,87-88$.

RAAB, D. H. Backward masking. Psychological Bulletin, 1963, 60, 118-129.

STREICHER, H. W.. \& POLLACK, R. H. Backward figural masking as a function of intercontour distance. Psychonomic Science, $1967,7,69-70$

STURR, J. F., \& FRUMKES, T. E. Spatial factors in masking with black or white targets. Perception \& Psychophysics, 1968. 4. 282-284.

WERNER, H. Studies on contour: 1. Qualitative analyses. American Journal of Psychology, $1935,47,40-64$.

\section{NOTES}

1. Supported by NIH Grant NB 07622-03. Based on a paper presented at the meetings of the Midwestern Psychological Association, Chicago, May 1969.

2. The target areas employed in the present study are well within the range of values within which the positive relation between target area and detectability holds in simple detection experiments. 